\title{
Molecular studies of Anopheles culicifacies (Diptera: Culicidae) in Sri Lanka: Sibling species $B$ and $E$ show sequence identity at multiple loci
}

\author{
SinNathamby Noble SURENDRAN ${ }^{1,2}$, Nicola J. HAWKES ${ }^{2}$, ANDREW STEVEN ${ }^{2}$, JANET HEMINGWAY ${ }^{2}$ \\ and RANJAN RAMASAMY ${ }^{3}$ \\ ${ }^{1}$ Department of Zoology, University of Jaffna, Jaffna, Sri Lanka; e-mail: noble@jfn.ac.lk \\ ${ }^{2}$ Liverpool School of Tropical Medicine, Pembroke Place, Liverpool, L3 5QA, UK \\ ${ }^{3}$ Institue of Medicine, University of Brunei, Jalan Tunku Link, Gadong BE1410, Brunei Darussalam
}

Key words. Anopheles culicifacies, species B, species E, Y-chromosome dimorphism, cytochrome oxidase II, ITS2, 28S rDNA, guanylate cyclase

\begin{abstract}
The anomaly that Anopheles culicifacies (Diptera: Culicidae) species B is a major vector of malaria in Sri Lanka, but a non-vector in India, has been noted for several years. In 1999, a Y chromosome dimorphism associated with Plasmodium vivax infectivity within the Indian A. culicifacies species B suggested that this was itself a complex of two sibling species, B and E. A recent cytogenetic analysis shows the sympatric presence of these sibling species in Sri Lanka, a situation similar to that reported from nearby Rameshwaram Island, India. Species E, with a submetacentric $\mathrm{Y}$ chromosome, is a more effective vector of $P$. vivax than species B with an acrocentric Y chromosome. Larval karyotyping, however, is time-consuming and labour-intensive. Recently, the development of a PCR-RFLP assay distinguishing species B and E of A. culicifacies from India, based on differences in one region of the cytochrome oxidase subunit II (COII) gene, was reported. Here we show that whilst this diagnostic approach reveals polymorphism in Sri Lankan A. culicifacies, this variation is not correlated with Y chromosome karyotype. Hence this assay will not be useful for distinguishing species B and E in Sri Lanka. Further, we found no difference between the sequences of Sri Lankan specimens in any of three other regions (ITS2, D3 region of 28S rDNA, and guanylate cyclase intron) often used for species discrimination.
\end{abstract}

\section{INTRODUCTION}

Anopheles culicifacies Giles sensu lato (Diptera: Culicidae) is the main vector of malaria in Sri Lanka (Ramasamy et al., 1994; AHB, 2001). Until recently, only sibling species B was reported from Sri Lanka (Abhayawardana et al., 1996a), but in India species B is a poor vector of malaria (Subbarao et al., 1992). However, recent studies of $A$. culicifacies from Rameshwaram Island in India, which is in close proximity to Sri Lanka, found evidence for assortative mating correlated with cytogenetic variation. Plasmodium vivax sporozoite-positive females had mated only with males with submetacentric $\mathrm{Y}$ chromosomes. No malaria infections were found in mothers of acrocentric $Y$ males; these were designated species B and the submetacentric Y-chromosome vectors were designated species E (Kar et al., 1999). Subsequently Surendran et al. (2000) identified the same cytogenetic variants within $A$. culicifacies from Sri Lanka, established that species E could support the extrinsic cycle of both $P$. vivax and P. falciparum (Surendran et al., 2003) and also found that species $\mathrm{E}$ is more resistant to malathion than species B (Surendran et al., 2002). Since larval karyotyping is cumbersome and time consuming, the development of a molecular identification technique would be useful to differentiate the species. Recently, Goswami et al. (2005) reported a PCR-RFLP assay distinguishing species $\mathrm{B}$ and $\mathrm{E}$ of $A$. culicifacies from India, based on differences in one region of the cytochrome oxidase subunit II (COII) gene. The aim of this work was to investigate the variability in this and other loci in $\mathrm{A}$. culicifacies specimens from Sri Lanka.

\section{MATERIAL AND METHODS}

DNA was extracted from eight specimens; two previously karyotyped specimens each of species B and E (Surendran et al.,
2000) and 4 specimens of unknown karyotype. Specimens of known and unknown karyotype were collected from Pelawatta $\left(6^{\circ} 45^{\prime} \mathrm{N}, 81^{\circ} 10^{\prime} \mathrm{E}\right.$, District of Moneragala) and Tonigala $\left(7^{\circ} 50^{\prime} \mathrm{N}, 79^{\circ} 59^{\prime} \mathrm{E}\right.$, District of Puttalam). Adult mosquitoes were homogenised in $100 \mathrm{ml}$ LIVAK extraction buffer $(80 \mathrm{mM} \mathrm{NaCl}$, $5.48 \%(\mathrm{w} / \mathrm{v})$ sucrose, $1.57 \%(\mathrm{w} / \mathrm{v})$ Tris-base, $50.8 \mathrm{mM}$ EDTA, $0.5 \%(\mathrm{w} / \mathrm{v}) \mathrm{SDS})$ in $1.5 \mathrm{ml}$ Eppendorf tubes and samples were placed at $65^{\circ} \mathrm{C}$ for $30 \mathrm{~min} .14 \mu \mathrm{l}$ of $8 \mathrm{M}$ potassium acetate was added to the homogenates and incubated on ice for $30 \mathrm{~min}$, then centrifuged at $4^{\circ} \mathrm{C}$ for $20 \mathrm{~min}$ at $13,000 \mathrm{rpm}$. Supernatants were recovered and DNA was precipitated overnight by the addition of $400 \mu \mathrm{l}$ ethanol, then centrifuged at $4^{\circ} \mathrm{C}$ for $15 \mathrm{~min}$ at 13,000 $\mathrm{rpm}$. The supernatant was discarded and DNA pellets rinsed in $100 \mu \mathrm{l}$ cold $70 \%(\mathrm{v} / \mathrm{v})$ ethanol, then centrifuged at $4{ }^{\circ} \mathrm{C}$ for $5 \mathrm{~min}$ at 13,000 rpm. Pellets were dried and resuspended in $50 \mu \mathrm{TE}$ buffer ( $\mathrm{pH}$ 8.0).

Sequences of the mitochondrial cytochrome oxidase II (COII) gene from 5 sibling species A-E of A. culicifacies from India were retrieved from GenBank (accession numbers AJ519492, AJ518810, AJ519493, AJ519494, AJ534646) and aligned using MegAlign software within the Lasergene package (DNAStar Inc., Madison, USA). These 530 bp sequences corresponded to amino acid positions 31-206 of the full-length protein. From this alignment five point substitutions between Indian species B and E were detected. Primers COIIF1 (5'-TTTATTGCTTTTCCTTCTTTACG-3') and COIIR1 (5'-ATAAAACTATGATTTGCTCCAC-3') were designed so as to bind in conserved regions (from amino acid positions 75 to 206), using Primer 3 software (http: //frodo.wi.mit.edu/cgi-bin/primer3/primer3_www.cgi; Rozen \& Skaletsky, 2000). PCRs were performed in a final volume of $25 \mu \mathrm{l}$ using one unit of HotStar Taq DNA polymerase (Qiagen, Crawley, UK) in manufacturer's buffer supplemented to a final concentration of $2 \mathrm{mM} \mathrm{MgCl}_{2}, 0.4 \mathrm{mM}$ dNTPs (Promega, 
Southampton, UK) and $0.4 \mu \mathrm{M} \mathrm{F1}$ and R1 primers (SigmaGenosys, Pampisford, UK). 15 ng gDNA template was supplied. PCR conditions (GeneAmp PCR System 9600, Applied Biosystems, UK) were as follows: $95^{\circ} \mathrm{C} 15 \mathrm{~min}$ initial denaturation, 35 cycles of $\left(94^{\circ} \mathrm{C}\right.$ for $20 \mathrm{~s}, 50^{\circ} \mathrm{C}$ for $30 \mathrm{~s}, 72^{\circ} \mathrm{C}$ for $\left.45 \mathrm{~s}\right)$ followed by a final extension step of $72^{\circ} \mathrm{C}$ for $10 \mathrm{~min}$. Two fifths (initially, later one fifth) of the PCR product was visualised on a $1.5 \%(\mathrm{w} / \mathrm{v})$ agarose gel, the remainder of the PCR product was then purified using the QiaQuick PCR purification kit (Qiagen) and submitted directly for sequencing. The primers amplified a $400 \mathrm{bp}$ fragment, which was sequenced directly in both directions using the same primers. Sequences were analyzed using Lasergene software (DNAStar Inc., Madison, USA); sequence alignments were created using ClustalW http://www.ch.embnet. org/software/ClustalW.html. One fifth of the COII PCR product was digested with 5 units of DdeI (recognition site CTNAG; Promega, Southampton, UK) in manufacturer's recommended buffer for $2 \mathrm{~h}$ at $37^{\circ} \mathrm{C}$ and the entire reaction visualized on a $2 \%$ $(\mathrm{w} / \mathrm{v})$ agarose gel.

Three nuclear loci were also amplified and sequenced, using the primers and PCR conditions reported by Sharpe et al. (2000): a $390 \mathrm{bp}$ fragment from the D3 region of the ribosomal $28 \mathrm{~S}$ gene, a $480 \mathrm{bp}$ region of the ribosomal Internal Transcribed Spacer 2 (ITS2) and a 190 bp fragment encompassing an intron $(\sim 105 \mathrm{bp})$ of the guanylate cyclase gene. PCR products were purified as above and sequenced directly using the amplification primers.

\section{RESULTS}

\section{Cytochrome oxidase subunit II (COII)}

A 400 bp region of the $C O I I$ was amplified successfully from all 8 samples. Fig. 1A shows the results of DdeI digestion of the $400 \mathrm{bp} \mathrm{COII}$ fragment. There was no difference in the electrophoretic patterns from the karyotyped B and E samples (lanes 1-4), and two other samples of unknown karyotype also demonstrated this pattern (lanes 7 and 8). The band sizes (a doublet of $120 \mathrm{bp}$ and a single band of $160 \mathrm{bp}$ ) were exactly as would be predicted from the sequences of these COII products (Fig. 1B). The digestion pattern and sequence of these 6 samples match that shown by Indian species $\mathrm{E}$ (allowing for the difference in initial PCR product size; Goswami et al., 2005), although in that study the band sizes observed did not match those predicted from the sequence. Interestingly, 2 samples of unknown karyotype displayed a different digestion pattern (and sequence), akin to that seen by Goswami et al. for Indian species B (Fig. 1A, lanes 5 and 6, Fig. 1B). Thus there is polymorphism within this region of COII in A. culicifacies from Sri Lanka, but it does not correlate with Y karyotype.

Fig. 1B shows the sequences obtained from these samples. The five positions that are variable between sibling species B and $\mathrm{E}$ from India are numbered. Six Sri Lankan samples had identical sequences; these included all 4 samples of known karyotype (B and E) and the two samples of unknown karyotype that showed the same DdeI restriction pattern (lanes 7 and 8 in Fig. 1A; the sequence of these individuals is not illustrated in Fig. 1B since it matches that shown for the $\mathrm{B}$ and $\mathrm{E}$ specimens). From these 6 samples the sequence at 4 of the 5 variable positions (1-4) matched the Indian E variant.

The remaining two Sri Lankan specimens (of unknown karyotype) generated the same sequence, varying at two positions (2 and 3) from the other 6 samples. This difference includes the first DdeI recognition site (position 2), explaining the different restriction pattern seen in Fig 1A.

The sequences of these products have been deposited in GenBank, accession numbers AY879311 (the sequence from 6 of 8 samples) and DQ173154 from the 2 samples with a different DdeI genotype.

\section{Internal Transcribed Spacer 2 (ITS2)}

Goswami et al. (2005) did not find an RFLP within the ITS2 region that could differentiate Indian species B from $\mathrm{E}$ (there is just one nucleotide difference between them; GenBank accession numbers AJ534247, AJ534645). Within the Sri Lankan samples in this study there was no difference at all in sequence (data not shown) and all sequences matched those of Sri Lankan specimens (from sibling species B and E) deposited in GenBank (accession numbers AY167747, AY168883). These sequences correspond to the Indian species E variant at the single differential site.

\section{D3 region of $28 S$ rDNA}

The D3 region of the ribosomal $28 \mathrm{~S}$ gene was also investigated. In agreement with the results of Singh et al. (2004), who could distinguish species $\mathrm{A}$ and $\mathrm{D}$ from $\mathrm{B}, \mathrm{C}$, and $\mathrm{E}$ using this region but could not separate $B$ from $E$, we found no variation in sequence between the karyotyped $\mathrm{B}$ and $\mathrm{E}$ samples, nor indeed between any of the samples (data not shown). All sequences were identical to those from Indian sibling species B, $\mathrm{C}$ and $\mathrm{E}$. The sequence from these Sri Lankan samples has been deposited in GenBank, accession number DQ173155.

\section{Guanylate cyclase (gua)}

We also amplified and sequenced an intron from the guanylate cyclase gene, which has not previously been analysed for $A$. culicifacies as far as we are aware. All samples amplified this region successfully, however, not all samples generated reliable sequence coverage. Good sequences were obtained from 6 of 8 samples (one karyotyped B, 2 karyotyped E and 3 of the 4 samples with unknown karyotype). However, once again there were no sequence differences between any of the samples. The sequence from these Sri Lankan samples has been deposited in GenBank, accession number DQ173156. Of the Anopheles gua intron sequences within GenBank, the Sri Lankan A. culicifacies sequence is unsurprisingly more similar to other species within the Myzomyia series (46\%, 69\%, 55\% identity with the introns from $A$. varuna, $A$. aconitus, $A$. minimus; GenBank accession numbers AF194488, AF194487, AF194486, respectively) than to members of the $A$. gambiae species complex ( $10 \%$ identity to all members; A. gambiae AGU42614, A. merus AMU42621, A. arabiensis AAU42611, A. melas AMU42618, A. quadriannulatus AQU42623) (Fig. 2).

\section{DISCUSSION AND CONCLUSIONS}

In India, A. culicifacies sibling species B is a poor vector of malaria. The presence of a Y-chromosome variation (submetacentric and acrocentric types) was first identified on Rameshwaram Island, southern India in 1993 (Subbarao et al., 1993). Subsequently, Adak et al. (1997) reported widespread Y polymorphism in sibling species $\mathrm{B}$ and $\mathrm{C}$, with species $\mathrm{B}$ collections from 9 of 11 Indian mainland localities displaying varying proportions of the two types, and concluded that this alteration could not be used to distinguish $A$. culicifacies sibling species. Kar et al. (1999) first reported that, at least on Rameshwaram Island and close by, the sympatric populations showed assortative mating, with the male progeny of sporozoite-positive fieldcaught females never having acrocentric $Y$ chromosomes. Hence in this locality the two populations can be defined as sibling species. However, it was not until 2005 that a simpler molecular tool was developed. Goswami et al. (2005) found that a single nucleotide polymorphism in one region of the mitochondrial cytochrome oxidase subunit II (COII) gene segregated with karyotype in the 15 species E samples (from Ramesh- 
waram Island) and 24 species B samples (from Rameshwaram Island and 5 other localities). However, as these authors acknowledge, it is still unclear whether the $\mathrm{Y}$ chromosome variation seen at other Indian locations corresponds to the hitherto undetected presence of sibling species $\mathrm{E}$ at these sites, or to simple polymorphism.

In Sri Lanka, the existence of $A$. culicifacies (previously identified as sibling species B) with both submetacentric and acrocentric Y chromosomes was first demonstrated in 2000 (Surendran et al., 2000). Extrapolating from the results of Kar et

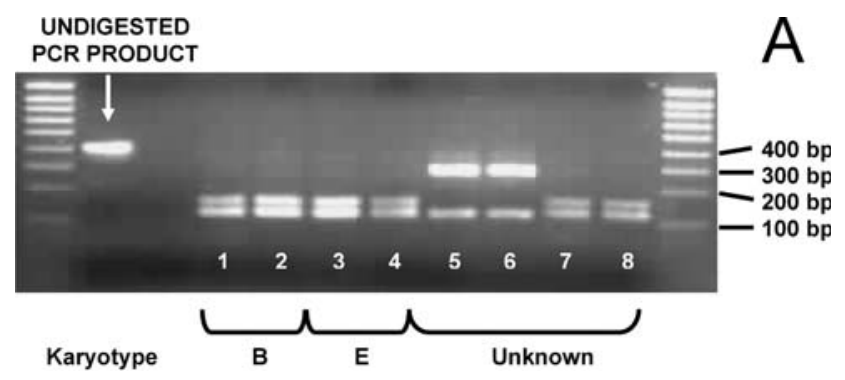

Coll-F1

COXIIACInd-B COXIIACInd-E COXIIACSL-B COXIIACSL-E COXIIACSL-UI

COXIIACIndCOXIIACInd-E COXIIACSL-BI COXIIACSL-E COXIIACSL-U1

COXIIACInd-B COXIIACInd-E COXIIACSL-B1 COXIIACSL-EI COXIIACSL-U1

COXIIAcInd-B COXIIACInd-E COXIIACSL-BI COXIIACSL-E COXIIACSL-U1

COXIIACInd-B COXIIACInd-E COXIIACSL-BI COXIIACSL-EI COXIIACSL-U1



(3)

Ddel

al. (1999), it was thus feasible that the submetacentric population (as species E) might also be responsible for malaria transmission in Sri Lanka. Subsequent data support this, with only the submetacentric population (species E) able to support the development of $P$. vivax and P. falciparum (Surendran et al., 2003), although assortative mating was not tested. In this pilot study, we tested the ability of the COII PCR-RFLP developed by Goswami et al. (2005) to differentiate species B and E collected from Sri Lanka. However, although there were sequence variations within the COII fragment equivalent to those seen in the Indian B and E specimens, the variation did not correlate with karyotype. In fact none of the four loci analysed herein (COII, ITS2, D3 region of 28S rDNA, and gua) differentiated between the samples of defined karyotype. Therefore, from our study it appears that the COII polymorphism detected in A. culicifacies from Sri Lanka cannot be used as a simple molecular tool to distinguish the sibling species, unlike the situation in India. A larger-scale analysis of the COII variability is clearly required. Very recently de Silva et al. (2005) reported that one Randomly Amplified Polymorphic DNA (RAPD) marker could distinguish B from E in Sri Lanka; this remains to be further characterized.

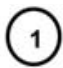

TTTATTGCTTTCCTTCTTTACGATTATTATATTAATGGACGAAATTAATACTCCTTCTATTACTTTAAAATCAATTGTCACCAAT TTTATTGCTTTTCCTTCTTTACGATTATTATATTTAATGGACGAAATTAATACCCCTTCTATTACTTTAAAATCAATTGGTCACCAAT

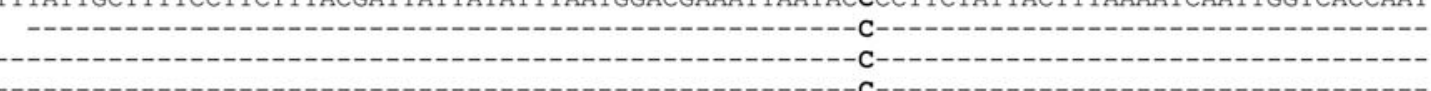

\section{Ddel}

GATATTGAAGTATGAATATTCTGATTTTTAAATTTAGAATTTGATTCTTACATAGTACCAACAAATGAACTTGAAACTAATGGATT GATATTGAAGTTATGAATATTCTGATTTTTAAACTTAGAATTTGATTCTTACATAGTACCAACAAATGAACTTGAAACTAATGGATT GAT

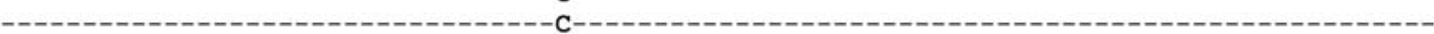

TCGTTTATTAGATGTAGATAATCGAGTTGTTTACCAATAAATAATCAAATTCGAATTTAGTAACAGCAACAGATGTACTTCATTC TCGTTTATTAGATGTAGATAATCGAATTGTTTTACCAATAAATAATCAAATTCGAATTTTAGTAACAGCAACAGATGTACTTCATTC
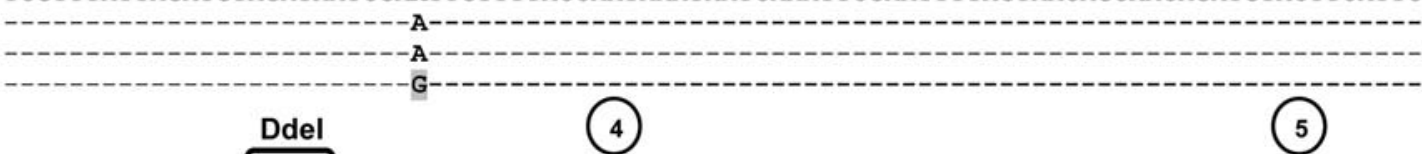

TTGAACTGTTCCTTCCTTAGGAGTAAAGGTTGATGCTTCACCAGGACGATTAAATCAAATTAATTTTTTAATTAATCGACCAGG TTGAACTGTTCCTTCCTTAGGAGTAAAGGTTGATGCTACACCAGGACGATTAAATCAAATTAATTTTTTAATTAATCGATCAGG

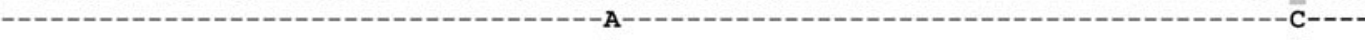

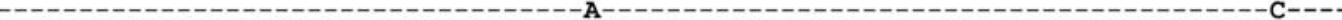

ATTATTTTTGGACAATGTTCAGAAATTTGGGAGCAAATCATAGTTTTAT ATTATTTTTTGGACAATGTTCAGAAATTTGTGGAGCAAATCATAGTTTTAT

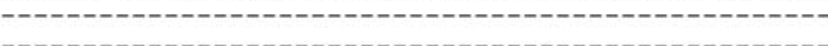

-

COII-R1

Fig. 1. Analysis of variation within the cytochrome oxidase subunit II region. A: DdeI digestion of COII fragments from samples of Y chromosome karyotype B (lanes 1, 2), E (lanes 3, 4) and unknown (lanes 5-8). B: Alignment of partial cytochrome oxidase II sequences from Indian Anopheles culicifacies sibling species B and E (accession numbers AJ518810, AJ534646, COXIIAcInd) with sequences from Sri Lankan A. culicifacies mosquitoes. The five positions varying between the two Indian species are indicated by circled numbers above, and in bold type; the less common variants are shaded. The two DdeI recognition sites are indicated; note that the first of these encompasses the second species-variable site. The positions of the primers used for amplification and sequencing are shown. The two Indian GenBank entries are given in full; for visual clarity sequence identity between these and the Sri Lankan samples is denoted by dashes. One sequence each from karyotyped B (COXIIAcSL-B1) and E (COXIIAcSL-E1) specimens are shown, since there was no variation between samples of each karyotype (nor in fact between the two Sri Lankan karyotypes). The COXIIAcSL-U1 sequence was obtained from the 2 samples of unknown karyotype, which displayed a different DdeI genotype (lanes 5 and 6 in Fig. 1A). The alignment was created using ClustalW http://www.ch.embnet.org/software/ClustalW.html. 


gambiae
merus
arabiensis
melas
quadriannulatus
aconitus
culicifacies
minimusA
varuna

gambiae
merus
arabiensis
melas
quadriannulatus
aconitus
culicifacies
minimusA
varuna

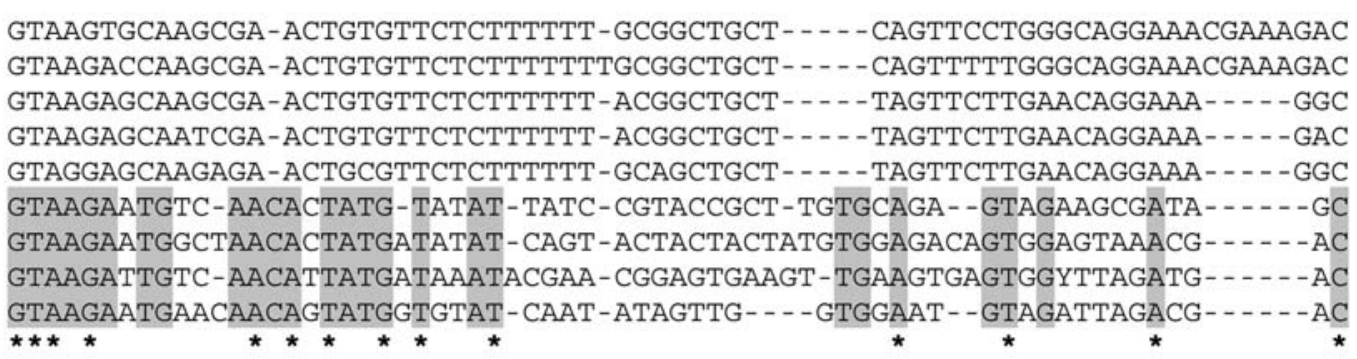

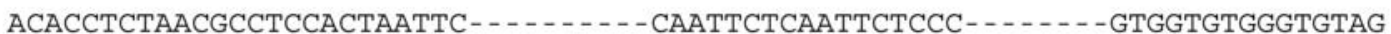

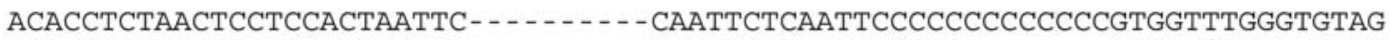

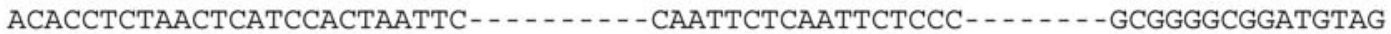

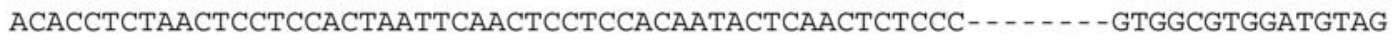

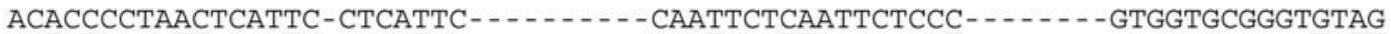
TCTTTC-TGAC-CGGTAGATAACAC $\ldots \ldots \ldots$ - $\ldots$ CGTTTTGCAACATGTTTGGTAACTC - - - - - - - TTCTCTGTGCTCGT $-\ldots$ TCTTTA-TAAC-AATTCGGTAACTT- TCTATGTACAC-CACT-
$\star \star$

Fig. 2. Alignment of the intron sequence from the guanylate cyclase gene from Anopheles culicifacies from Sri Lanka with members of the A. gambiae complex (A. gambiae, A. merus, A. arabiensis, A. melas, A. quadriannulatus) and from members of the Myzomyia series (A. varuna, A. aconitus, A. minimus). There are 21 sites conserved between all species (indicated by *), and further 19 sites conserved between the members of the Myzomyia series (shaded in grey). The alignment was created using ClustalW http://www.ch.embnet.org/software/ClustalW. html.

Incongruity between chromosomal and molecular types in Anopheles is the subject of much research. In A. gambiae sensu stricto reproductive isolation between sympatric populations is correlated with molecular differences rather than with the wellknown chromosomal forms (defined by various chromosome 2 inversions) (Favia et al., 1997; Toure et al., 1998; Gentile et al., 2001; della Torre et al., 2001). Whilst in some areas, e.g. Burkina Faso, there is good correlation between the molecular $\mathrm{M}$ and S forms and the chromosomal forms Mopti and Savanna (Favia et al., 1997), in many other regions this relationship breaks down (della Torre et al., 2001; Gentile et al., 2001). For example, in at least some areas of the Ivory Coast both molecular forms remain distinct even when sympatric populations are of the same chromosomal form (della Torre et al., 2001). With A. culicifacies the situation appears somewhat different: in India on Rameshwaram Island there is a correlation between chromosomal type, vectorial capacity and one molecular marker but this association may not hold in other geographical areas. In Sri Lanka, there is no molecular support as yet for the distinction between $\mathrm{B}$ and $\mathrm{E}$, but chromosomal and biological evidence for two populations of different vectorial capacity and insecticide resistance.

The other main vector of malaria in Sri Lanka is A. subpictus, also divided into sibling species. The two commonly described A. subpictus siblings show differential susceptibility to organophosphorus and pyrethroid insecticides; species A is abundant predominantly inland and moderately resistant to malathion and fenitrothion, whereas species B is confined to the coast and resistant to permethrin (Abhayawardana et al., 1996b; KellyHope et al., 2005). De Silva et al. (2005) have recently suggested the presence of two further sibling species within the $A$. subpictus complex as well as a molecular tool to differentiate one pair from another. However, differences in vectorial capacity have not been described.

It is clear that further molecular investigations of the Sri Lankan submetacentric and acrocentric Y populations are warranted. In A. gambiae, only 3 markers are useful for differentiating the molecular, reproductively isolated forms: the ribosomal intergenic spacer $(I G S)$, the internal transcribed spacer (ITS - both ITS1 and ITS2) and the knockdown resistance allele (della Torre et al., 2001, Gentile et al., 2001). No other fixed changes between the forms were detected in a sequencing scan of more than $6 \mathrm{~kb}$ spanning 6 other genes, including the COII gene and the gua intron (Gentile et al., 2001) studied herein. A recent study using microarray analysis suggests that just three small regions of the $A$. gambiae genome, containing 67 genes in total, are linked with speciation (Turner et al., 2005). Clearly it will be of great interest ultimately to determine if the genes involved in delineating the A. gambiae forms are also responsible for the sibling speciation described in $\mathrm{A}$. culicifacies.

ACKNOWLEDGEMENTS. We thank A. Ball and A. Parsley for sequencing services at LSTM. S.N. Surendran was supported by a training fellowship from the Science and Technology Personnel Development Project of the Government of Sri Lanka.

\section{REFERENCES}

Abhayawardana T.A., Dilrukshi R.K.C. \& Wijesuriya S.R.E. 1996a: Cytotaxonomic examinations for sibling species in the taxon Anopheles culicifacies Giles in Sri Lanka. Indian J. Malariol. 33: 74-80.

Abhayawardana T.A., Dilrukshi R.K.C. \& Wijesuriya S.R.E. 1996b: Anopheles subpictus complex: distribution of sibling species in Sri Lanka. Indian J. Malariol. 33: 53-60.

AHB 2001: Annual Health Bulletin. Public Health Services, Ministry of Health, Sri Lanka, pp. 46-49.

Adak T., Sarbjt K., Wattal S., Nanda N. \& Sharma V.P. 1997: Y-chromosome polymorphism in species B and C of the Anopheles culicifacies complex. J. Am. Mosq. Control. Assoc. 13: 379-383.

De Silva B.G.D.N.K., Munasinghe M.P.C.S., Weerasuriya G.D.N.G., Ariyawansha W.G.S., Wickramasinghe M.B. \& Karunanayake E.H. 2005: Sibling species status of Anopheles culicifacies and Anopheles subpictus and their distribution in Sri Lanka. In: EMBO Workshop "Molecular and 
Population Biology of Mosquitoes and Other Disease Vectors". Kolymbari, Crete, Greece.

della Torre A., Fanello C., Akogbeto M., Dossou-yovo J., Favia G., Petrarca V. \& Coluzzi M. 2001: Molecular evidence of incipient speciation within Anopheles gambiae s.s. in West Africa. Insect Mol. Biol. 10: 9-18.

Favia G., Della Torre A., Bagayoko M., Lanfrancotti A., SAGNON N.F., Toure Y.T. \& Coluzzi M. 1997: Molecular identification of sympatric chromosomal forms of Anopheles gambiae and further evidence of their reproductive isolation. Insect Mol. Biol. 6: 377-383.

Gentile G., Slotman M., Ketmaier V., Powell J.R. \& Caccone A. 2001: Attempts to molecularly distinguish cryptic taxa in Anopheles gambiae s.s. Insect Mol. Biol. 10: 25-32.

Goswami G., Raghavendra K., Nanda M.N., Gakhar S.K. \& SubBaRAo S.K. 2005: PCR-RFLP of mitochondrial cytochondrial oxidase subunit II and ITS2 of ribosomal DNA: Markers for the identification of members of the Anopheles culicifacies complex (Diptera: Culicidae). Acta Trop. 95: 92-99.

Kar I., Subbarao S.K, Eapen A., Ravindran J., Satyanarayana T.S., Raghavendra K., Nanda N. \& Sharma V.P. 1999: Evidence for a new vector species within the Anopheles culicifacies complex (Diptera: Culicidae). J. Med. Entomol. 36: 595-600.

Kelly-Hope L.A., Yapabandara A.M.G.M., Wickramasinghe M.B., Perera M.D.B., Karunaratne S.H.P.P., Fernando W.P., Abeyasinghe R.R., Siyambalagoda R.R.M.L.R., Herath P.R.J., Galappaththy G.N.L. \& Hemingway J. 2005: Spatiotemporal distribution of insecticide resistance in Anopheles culicifacies and Anopheles subpictus in Sri Lanka. Trans. R. Soc. Trop. Med. Hyg. 99: 751-761.

Ramasamy R., Ramasamy M.S., Wijesundera D.A., WiJesundera A.P., Dewit I., Ranasinghe C., Srikrishnarajah K.A. \& Wickramarantne C. 1994: High seasonal malaria transmission rates in the intermediate rainfall zone of Sri Lanka. Ann. Trop. Med. Parasitol. 86: 591-600.

Rozen S. \& Skaletsky H.J. 2000: Primer3 on the WWW for general users and for biologist programmers. In Krawetz S. \& Misener S. (eds): Bioinformatics Methods and Protocols: Methods in Molecular Biology. Humana Press, Totowa, NJ, pp. 365-386.
Sharpe R.G., Harbach R.E. \& Butlin R.K. 2000: Molecular variation and phylogeny of members of the Minimus group of Anopheles subgenus Cellia (Diptera: Culicidae). Syst. Entomol. 25: 263-272.

Singh O.P., Goswami G., Nanda MN., Raghavendra K., Chandra D. \& Subbarao S.K. 2004: An allele-specific polymerase chain reaction assay for the differentiation of members of the Anopheles culicifacies complex. J. Biosci. 29: $275-280$.

Subbarao S.K., Vasantha K., Joshi H., Raghavendra K., Devi C.U., Satyanarayana T.S., Cochrane A.H., Nussentweig R.S. \& SHARma V.P. 1992: Role of Anopheles culicifacies sibling species in malaria transmission in Madhya Pradesh, India. Trans. R. Soc. Trop. Med. Hyg. 86: 613-614.

Subbarao S.K., Nanda N., Chandrahas R.K. \& Sharma V.P. 1993: Anopheles culicifacies complex: cytogenetic characterisation of Rameshwarm Island population J. Am. Mosq. Control Assoc. 9: 27-31.

Surendran S.N., Abhayawardana T.A., De Silva B.G.D.N.K., RAMASAMY M.S. \& RAMASAMY R. 2000: Anopheles culicifacies $\mathrm{Y}$ chromosome dimorphism indicates the presence of sibling species (B and $\mathrm{E}$ ) with different malaria vector potential in Sri Lanka. Med. Vet. Entomol. 14: 437-440.

Surendran S.N., De Silva B.G.D.N.K., Ramasamy M.S. \& RAMASAMY R. 2002: Differential susceptibility to malathion by two members (B and E) of the Anopheles culicifacies (Diptera: Culicidae) species complex in Sri Lanka. Proc. Sri Lanka Assoc. Advmt. Sci. 58: 153.

Surendran S.N., de Silva B.G.D.N.K., Srikrishnarajh K.A., RAMASAMY M.S. \& RAMASAMY R. 2003: Establishment of species $\mathrm{E}$, not $\mathrm{B}$ as the major vector of malaria in the Anopheles culicifacies complex in the country. Proc. Sri Lanka Assoc. Advmt. Sci. 59: 18.

Toure Y.T., Petrarca V., Traore S.F., Coulibaly A., Maiga H.M., Sankare O., Sow M., Di Deco M.A. \& Coluzzi M. 1998: Distribution and inversion polymorphism of chromosomally recognized taxa of the Anopheles gambiae complex in Mali, West Africa. Parasitologia 40: 477-511.

Turner T.L., Hahn M.W. \& Nuzhdin S.V. 2005: Genomic islands of speciation in Anopheles gambiae. PLoS Biol 3: 285.

Received December 16, 2004; revised and accepted September 28, 2005 